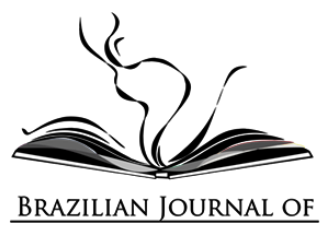

\title{
RACISMO EN CUBA: UN ANÁLISIS DESDE EL NÚMERO 2/2017 DE LA REVISTA EL MAR Y LA MONTAÑA, EN GUANTÁNAMO
}

\author{
RACISMO EM CUBA: UMA ANÁLISE DO NÚMERO 2/2017 DA REVISTA EL \\ MAR Y LA MONTAÑA, EM GUANTÁNAMO \\ RACISM IN CUBA: AN ANALYSIS OF ISSUE 2/2017 OF THE MAGAZINE EL \\ MAR Y LA MONTAÑA, IN GUANTÁNAMO
}

Mariurka Maturell Ruiz' (iD

Lisandro René Duvergel Smith ${ }^{2}$ iD Universidade Federal de Santa Catarina, Brasil

\begin{abstract}
Resumen: Analizar las narrativas de las publicaciones sobre racismos y discriminación racial en el número 2/2017 de la Revista El Mar y la Montaña de Guantánamo desvenda la pertinencia y actualidad de estos debates en Cuba. De igual manera, las publicaciones en la revista nos aproximan a las brechas ocultas y/o poco exploradas del tema racial en la realidad social cubana, a través de los temas: la subversión anticubana; el pensamiento y discurso afrofeminista; el debate en torno al término afrocubano/a; la presencia africana; las cuestiones raciales en la cultura Rastafari y los avances y retrocesos en la lucha antirracista. El tema racial, en Cuba, aún causa inconvenientes y provoca posicionamiento acalorados, como consecuencia de la invisibilidad que se creó, por décadas, alrededor de este. Esto se debe, entre otras razones, a un idealismo revolucionario que dio por resuelto "el problema racial", al concebirse una política de igualdad social que desde el punto de vista clasista otorgaba los mismo derechos y deberes sin distinción de raza o género a todas las personas. Partiendo de estas cuestiones se indaga en las categorías racismo y discriminación racial, a través, del análisis de las publicaciones del número 2/2017 de la Revista El Mar y la Montaña. Para ello se utilizó el método Análisis de Contenidos.
\end{abstract}

Palabras clave: Publicaciones locales; Debates raciales; Racismo; Discriminación; Afrocubano/a.

Resumo: As análises das narrativas das publicações sobre racismos e discriminação racial no número 2/2017 da Revista El Mar y la Montaña de

\footnotetext{
' Doctorante del Programa de Posgraduación en Historia, Universidade Federal de Santa Catarina (UFSC). E-mail: mariurkamaturell@gmail.com.

${ }_{2}^{2}$ Maestrante del Programa de Posgraduación en Historia, Universidade Federal de Santa Catarina (UFSC).
} 
Guantánamo desvenda a pertinência e atualidade desses debates em Cuba. Da mesma forma as publicações aproximam as lacunas ocultas e poucas exploradas do tema racial na realidade social cubana, através dos tópicos tratados: subversão anticubana, pensamento e discurso afro-feminista, debate em torno do termo afro-cubano/a, presença africana, questões raciais na cultura Rastafari e avanços e retrocessos na luta antirracista. A temática racial em Cuba ainda causa incômodos e provoca posicionamentos acalorados, como consequência da invisibilidade que se criou, por décadas, ao redor desta temática. Isto se deve, entre outras razões, ao idealismo revolucionário, que considerou "o problema racial" resolvido, ao conceber-se uma política de igualdade social, que do ponto de vista classista outorgava os mesmos direitos e deveres sem distinção de raça ou gênero a todas as pessoas. A partir dessas questões, são interrogadas as categorias racismo e discriminação racial, desde a análise das publicações de número 2/2017 da Revista El Mar y la Montaña. Para conseguir isso, usamos o método Análise de Conteúdo.

Palavras clave: Publicações locais; Debates raciais; Racismo; Discriminação; Afro-cubano/a.

Abstract: Analyzing the narratives of the publications on racism and racial discrimination in issue 2/2017 of the Magazine El Mar y la Montaña de Guantánamo exposes the relevance and actuality of these debates in Cuba. In the same way, the publications in the magazine bring us closer to the hidden and / or little explored gaps of the racial issue in the Cuban social reality, through the topics: anti-Cuban subversion; Afro-feminist thought and discourse; the debate around the term Afro-Cuban; the African presence; racial issues in Rastafarian culture and advances and setbacks in the fight against racism. The racial issue, in Cuba, still causes inconveniences and causes heated positioning, because of the invisibility that was created, for decades, around it. This is due, among other reasons, to a revolutionary idealism that considered "the racial problem" resolved, by conceiving a policy of social equality that from the class point of view granted the same rights and duties without distinction of race or gender to all people. Starting from these questions, the categories racism and racial discrimination are investigated, through the analysis of the publications of number 2/2017 of the Magazine El Mar y la Montaña. For this, the Content Analysis method was used.

Keywords: Local publication; Racial debates; Racism; Discrimination; Afro-Cuban. 


\section{Para una presentación oportuna}

En 2017, el crítico literario nacido en Guantánamo (Cuba), Rissell Parra Fontanilles escribió el artículo: La editorial Revista El Mar y la Montaña. Los tiempos del Génesis para celebrar los 30 años de la Editorial El Mar y la Montaña, de Guantánamo. En el artículo hizo referencia a la dimensión del trabajo realizado por los/as especialistas que como él participan y han participado de la edición de la revista que lleva el mismo nombre que la editorial, El Mar y la Montaña. Al mismo tiempo, dejó escapar la fuerte carga simbólica que habita en cada ejemplar de la revista que circula entre los lectores desde hace tres décadas. Para Parra (2017) "todo hecho cultural es el resultado de un largo proceso de búsqueda y sedimentación, de escalones que ascienden y descienden de rellanos y zigzags, de retrocesos y estancamientos, es un quehacer que en general representa una continuación de ideas, instituciones y costumbres en la vida de los pueblos" (p. 27).

La revista El Mar y la Montaña emerge en el año 1987, junto al suplemento informativo Debate del Periódico Venceremos y a la revista Señales, publicaciones de amplias proyecciones artísticas que sirvieron de detonador para la visualización del quehacer cultural en el territorio. Es importante resaltar que para la década de los ochenta de cada uno de estos medios le confirió al contexto guantanamero la fisonomía de una época fructífera, mientras circulaban. En este escenario la revista responde a la demanda, de los/as autores/as, creadores/as y demás actores/actrices socioculturales, de tener un medio para divulgar sus producciones. Ante lo que significa la revista el artista plástico y diseñador George Pérez ${ }^{3}$, nos dice en la entrevista que dio para José Raúl Fraguela" (2017b, p. 27): "[...] si no es ella ¿quién nos publicaría?, ¿Quién reseñaría nuestro trabajo?,

\footnotetext{
${ }^{3}$ Artista de la vanguardia guantanamera de reconocido prestigio nacional e internacional. Formó parte, como diseñador, del grupo que creó la revista.

${ }_{4}^{4}$ Poeta, escritor para niños, crítico literario y editor de la revista El Mar y la Montaña.
} 
¿Quién escribiría sobre el desarrollo de nuestra vasta y polifacética cultura? He ahí su importancia, lo que valida su existencia."

Su existencia está marcada por varias etapas en que circuló con sistematicidad, a pesar de las dificultades financieras y la ausencia de personas especializadas que se ocuparan de su edición, diseño e impresión. Tuvo una primera época que abarcó desde febrero de 1987- 1989; la segunda entre 1991 y 1992; la tercera de 1997 hasta el 2001 y una última que comenzó desde el 2002 hasta la actualidad (MATURELL, 2016). Impresa por primera vez en el Combinado Poligráfico Juan Marinello de la ciudad de Guantánamo, de la mano de un pequeño equipo de trabajo que pretendía con un estilo simple hacer realidad la idea de "contar con una publicación en la provincia, donde los creadores en su mayoría escritores y también artistas plásticos pudieran mostrar su obra además de servir de puente divulgativo del acontecer cultural del territorio", como argumenta George Pérez en la entrevista para Fraguela (2017b, p. 30).

Es a partir del año 2002, que su publicación consigue tener una periodicidad estable, con la llegada de las editoriales territoriales y la confluencia de una nueva generación de especialistas preparados para enfrentarse a las nuevas exigencias. Cabe destacar que en el año 2000, después de una reunión del Comandante en Jefe Fidel Castro Ruz con directivos de Cultura y del Instituto Cubano del Libro, se decide organizar en cada provincia, las Ilamadas Ediciones Territoriales o Editoriales Provinciales ${ }^{5}$, como más se conocen, para impulsar en los municipios las experiencias que propician la preservación de los signos de identidad, la protección de los valores patrimoniales y la promoción de los talentos artísticos y literarios locales, porque "estamos en condiciones de librar una guerra de todo el pueblo por la cultura" (CASTRO, 1999, p. 1). En la actualidad, todas las provincias cuentan con editoriales capaces de facilitar las publicaciones de cada territorio.

\footnotetext{
${ }^{5}$ En las editoriales provinciales se producen y potencian conocimientos derivados de los saberes locales y por consiguiente se presta mayor atención a la visualización de autores/as desconocidos o con escasas posibilidades de publicación y a la generación de nuevos lectores.
} 
Ahora bien, los festejos por los 30 años de existencia de la revista fueron un espacio oportuno para mostrar nuevas facetas del acontecer cultural en el territorio y su vínculo con otras geografías culturales. En este sentido, el segundo número de la revista en el año 2017 se convierte en el canal idóneo para la confluencia de diversas narrativas sobre la problemática racial en Cuba y en Guantánamo y en la fuente principal de este artículo. Para Fraguela (2017a), en las publicaciones del número 2/2017 de la revista, objeto del estudio del artículo que aquí se presenta, se encuentran opiniones divergentes o al menos con muy diversos matices que se han generado en torno al tema racial.

De ahí que, para los autores de este artículo sea vital, como guantanameros, aportar a la socialización de los conocimientos que sobre la temática son generados en las localidades. Por ello se pretenden analizar los contenidos que subyacen en las publicaciones sobre racismos y discriminación racial en el número 2/2017 de la Revista de arte y literatura El Mar y la Montaña de Guantánamo, Cuba, como objetivo general. Para concretar este objetivo, se escudriña, con base en el método Análisis de Contenidos, en los artículos publicados con los temas siguientes: subversión anticubana; pensamiento y discurso afrofeminista; debate en torno al término afrocubano/a; presencia africana; cuestiones raciales en la cultura Rastafari; y avances y retrocesos en la lucha antirracista en el contexto cubano.

En este sentido, se seleccionaron las categorías de análisis y por consiguiente las subcategorías a partir de la organización de las narrativas de las publicaciones. Las mismas responden al interés de la investigación y se apoyan teóricamente en la combinación de criterios que sugieren Laurence Bardin (2004) y Jorge Ruiz Ruiz (2009). De manera que Laurence Bardin (2004) permite profundizar en el procedimiento del análisis del contenido de las publicaciones para un mejor entendimiento de los significados latentes y de la verificación de relaciones teóricas. Dentro de 
este orden de idea Ruiz (2009) hace notar que "la selección de los tópicos pertinentes, el orden de su aparición, el tiempo dedicado a cada uno de ellos, las relaciones que se establecen entre los distintos temas o su modo de aparición (espontánea o sugerida), son cuestiones muy importantes para la caracterización de los discursos" (p. 7). De ahí que el análisis de los contenidos que subyacen en las publicaciones sobre racismos y discriminación racial en el número 2/2017 fue organizado por fases. Primera fase: Organización del material objeto de análisis; Segunda fase: Selección de las categorías, los indicadores y de las unidades de análisis; Tercera fase: Análisis de los materiales y Cuarta fase: Presentación de los resultados.

De igual modo, el estudio que aquí se presenta se apoyó en la consulta de documentos bibliográficas que son de obligatoria consulta para abordar el tema del racismo y la discriminación en Cuba. Es importante acotar que la problemática racial en Cuba ha sido motivo de discusión de intelectuales, académicos/as, investigadores/as y activistas residentes en el país, de cubanos/as, en el exterior y de extranjeros/as que se interesan por los asuntos de la realidad social cubana. Entre los/as que se destacan: Cecilia Bobes (1996); Pablo Rodríguez Ruiz e Rodrigo Espina Prieto (2006); Tomás Fernández Robaina (2014, 2017); Alejandro de la Fuente (2001); Nancy Morejón (2014); Esteban Morales Domínguez (2015; 2017a; 2017b); Roberto Zurbano (2015, 2019); entre otros/as.

Como se constató en la revisión bibliográfica y en concordancia con lo acotado por Fernández Robaina (2014) el tema racial en Cuba continúa demandando una mayor apertura y diversificación de los debates públicos, en todos los niveles de enseñanza y sobre todo en los medios de comunicación masiva, que son los que reflejan la realidad circundante. Esta afirmación cobra total sentido y pertinencia entre los argumentos del intelectual antirracista Roberto Zurbano (2015, p. 17), cuando expone que,

[...] La ausencia de un debate público que involucre diversas instancias (sociales, científicas, políticas) que expliquen, asuman críticamente y propongan soluciones al racismo, que nunca desapareció del todo, oculto entre los pliegues de un silencio disciplinario, fortaleció y propició la mutación de viejas ideas 
racistas que hoy encuentran el momento adecuado para reinsertarse cómodamente en la sociedad, engendrando un nuevo racismo en una nueva sociedad.

En función de situar la aseveración de Zurbano (2015), se hace importante destacar que el racismo y la discriminación racial, en Cuba, tienen su génesis en la esclavitud del negro/a como en el resto de los territorios de las Américas. Durante muchos años las personas negras y su descendencia ocupaban la posición más baja y deprimente en las sociedades colonial y republicana. En esos contextos ser negro/a y africano/a era sinónimo de pobreza, sumisión y subordinación. Sin embargo, después de 1959 esta situación adquirió nuevos matices, que le confirieron otras condicionantes al racismo y a la discriminación, y por consiguiente connotaciones diferentes a las que tiene en otras geografías. Este fenómeno social coexistió dentro de un proyecto social y económico socialista, ${ }^{6}$ construido desde la idea de una única nación, con base en la igualdad para todos, para dar continuidad al pensamiento de José Martí y de Antonio Maceo sobre la unión de todos los cubanos para lograr la independencia. ${ }^{7}$

Una nación homogénea tanto en lo político como en lo cultural, que dio fin a la discriminación racial cuando facilitó oportunidades de trabajo para todos/as los/as cubanos/as, sin discriminación de razas o de sexo. La misma, que se adhirió a la convocatoria del líder de la Revolución, Fidel Castro, para cesar con la discriminación racial en los centros de trabajo, y que blancos y negros se pusieran todos de acuerdo para juntarse en un mismo objetivo: poner fin a la odiosa discriminación racial ${ }^{8}$. A pesar de ello,

\footnotetext{
${ }^{6}$ Para profundizar véase: Partido Comunista de Cuba (2011; 2017).

${ }^{7}$ Entre las ideas de lograr la independencia de José Martí sobre la unión de todos los cubanos, se destacan su pensamiento dirigido a evitar el "miedo a los negros", basado en el hecho de que ser cubano es más que ser blanco o que ser negro. Igualmente, Antonio Maceo defendió la idea de no pedir nada a los negros porque todos los cubanos tenemos sólidas razones para que cubanos de buena voluntad, blancos y negros, crean que la única forma de solucionar los problemas sociales negros se puede lograr con una revolución.

${ }^{8}$ Con el Triunfo de la Revolución las personas en Cuba se dictaron un conjunto de medidas que garantizarían la igualdad de derechos y deberes a todos/as sin distinción de raza o género, entre ellas se destacan: la eliminación de los exclusivismos raciales existente en clubes y asociaciones, lo que vino anunciado con el proceso de nacionalización en 1961; la Ley de Reforma Urbana en 1960, protegía al usufructuario, le concedía la propiedad de la vivienda y permitía la ejecución de diversos programas de construcción de vivienda para los trabajadores; la Ley de Reforma Agraria en 1959, que hizo propietario de la tierra a campesinos y arrendatarios, beneficiando a trabajadores rurales negros y mestizos que hasta el momento eran excluidos del derecho a poseer la propiedad
} 
las proclamas para la desaparición del racismo como portavoz de la igualdad de todos los cubanos y cubanas como se verá en este estudio, no fueron suficientes para erradicarlo. En consecuencia,

[...] en el debate público el tema estaba fuera de lugar y la sentencia fue legitimada por la ciencia a través de trabajos que informaron un problema superado. "La discriminación racial en Cuba nunca volverá" (Felipe José Cameado, 1962). "Un mal pasado, aspecto de la discriminación racial" (Juan Sanchés, 1972). En la revista Bohemia de Juan René Betancout (1973) "El ciudadano negro del futuro" y de Pedro Servait (1986) "El problema negro en Cuba y su solución definitiva". Todos estos trabajos destacaron el papel de la Revolución en la superación de las desigualdades debidas a la raza." (ALMEIDA JUNCO, 2011, p. 141)

En este sentido, el racismo ${ }^{9}$ se vio contestado por la estructuración de un discurso sociopolítico que proclamó la igualdad y estigmatizó todas las formas de exclusión, incluidas las raciales (ESPINA PRIETO; RODRÍGUEZ RUIZ, 2006), además de parcializar las respuestas a la pregunta: ¿Existe racismo en Cuba? Para los defensores a ultranza de la Revolución y sus conquistas, la negación del problema racial era la respuesta. Aunque reconocían su existencia, preferían silenciar el racismo, porque era solo un asunto de personas prejuiciosas, del otro/a, del espacio privado, no de la Revolución. Sin embargo, con los cambios ocurridos en la sociedad cubana tras la caída del campo socialista a finales de los 80 , e iniciada la crisis a principio de los 90, el tema racial gana en visibilidad. En otras palabras, la crisis económica que colapsó al país, luego del colapso del campo socialista (1989), acentúo las desigualdades sociales y, en consecuencia, las raciales. ${ }^{10}$

de la tierra en que laboraban; el proceso de alfabetización de la población en 1961, junto a la universalidad de la enseñanza gratuita y obligatoria para todos/as; la extensión de los servicios de salud gratuitos para toda la población; etc. Dichas medidas ratificaban el carácter popular del proceso y redujo al mínimo la desigualdad social.

9 "O racismo é uma forma sistemática de discriminação que tem a raça como fundamento, e que se manifesta por meio de práticas conscientes ou inconscientes que culminam em desvantagem ou privilégios para indivíduos, a depender do grupo ao qual pertençam" (ALMEIDA, 2019, p. 32). De esta definición se interpreta que cualquier individuo puede ser discriminado por su raza, entiéndase raza como una construcción social y política que opera a través de lo biológico y lo cultural para atribuirles a los individuos características diferenciadoras que denotan la superioridad de unos con relación a otros, apoyado, por un lado, en rasgos físicos como el color de la piel y por otro en origen, religión, hábitos, etc. Para un mayor acercamiento al análisis del término ver: ALMEIDA (2019); MOORE (2007); NARANJO OROVIO et al. (2020). De igual manera existen otras fuentes bibliográficas que muestran cómo opera el racismo, entre ellas: DAVIS (2016); MOREIRA (2019); RIBEIRO (2018), por solo citar algunas. ${ }_{10}$ Cuba finaliza la década del 80 e inicia la del 90 bajo un modelo de economía centralizado basado en un patrón de inserción internacional dependiente y concentrado en las fuentes que provenían de la Unión Soviética. Por tanto, el derrumbe o colapso del campo socialista, en 1989, puso al país frente a una crisis económica sin precedentes en la historia de la Revolución, dando paso al Ilamado "Periodo Especial". "El colapso socialista, precedido en Cuba por la recesión que causó el giro anti mercado del Proceso de Rectificación (1986-1990), así 
No obstante, aun cuando en otras latitudes (como en Brasil o en EE. UU., por ejemplo) el racismo es estructural, o sea, está presente en la organización económica y política de la sociedad (ALMEIDA, 2019), en Cuba se manifiesta a través de las instituciones. Según Rolando Rensoli (2015),

[...] El empoderamiento en cargos de dirección de una persona con prejuicios raciales, puestos decisores, sistema judicial, plazas de atención a clientes o usuarios o en el proceso docente- educativo, puede provocar exclusiones y discriminaciones. De hecho, se ha constatado su ocurrencia. Incluso aunque en la filosofía de una entidad pública no esté prevista la discriminación esa posibilidad se concreta al ejercer el poder de una persona prejuiciosa y de ahí que puede el racismo tornarse con ropas institucional aun cuando el proceso revolucionario sea diametralmente opuesto a toda discriminación en sus principios. (p. 16)

Dentro de este marco, a toda la problemática racial se le une la persistencia de los prejuicios, anclados en la subjetividad de las personas. De manera que con todo lo expuesto hasta aquí, concordamos con el profesor y abogado brasileño Silvio Almeida (2019), cuando esclarece que el racismo se articula con la segregación racial, es decir, con la división espacial de las razas en localidades específicas (barrios, guetos, periferias, etc.), al mismo tiempo que se concibe desde su relación con la subjetividad, el Estado y la economía. Dicho de otro modo, en la medida que conocemos de la existencia y materialización de actos constantes y sistemáticos de discriminación racial, confirmamos que aquella ideología de supremacía racial colonial vestida de racismo sigue en presente continuo, porque ha subsistido a través del tiempo, anclado en prácticas sociales concretas.

En este sentido, las personas negras, en Cuba, ocupan en determinados sectores de la sociedad posiciones de desigualdad que las colocan en desventaja con relación a otros grupos. Por ejemplo, en el sector

como la incapacidad del modelo cubano para generar crecimiento económico sostenible, expandir y diversificar las exportaciones y lograr una sustitución de importaciones, provocaron una severa crisis que tocó fondo en 1993. Debido a eso y a pesar de los esfuerzos del gobierno, virtualmente todos los indicadores sociales se deterioraron" (MESA-LAGO, 2005, p. 184) y como consecuencia se incrementaron las desigualdades y el resurgimiento del problema de la pobreza. Cf. Artículo Problemas sociales y económicos en Cuba durante la crisis y la recuperación de Carmelo Mesa-Lago 
emergente de la economía, como el sector turísticon", a decir de Rodrigo Espina Pietro y Pablo Rodríguez Ruiz (2006), la proporción de personas negras y mestizas entre los dirigentes es baja. Según estos investigadores, existe una desproporción de profesionales y técnicos negros y mestizos que no está sujeta a la calificación de estos, sino a la adición de premisas o elementos de juicio, que se añaden de la existencia de barreras u obstáculos para la población negra ante determinadas condiciones sociales que han permitido su configuración

\section{2. análisis de las publicaciones del número $2 / 2017$ de la revista EI mar y la montaña}

En Cuba los asuntos que contornan la problemática racial, en las localidades que están geográficamente distante de la capital del país, han alcanzado notoriedad dentro de las políticas editoriales a nivel nacional, en correspondencia con las exigencias de las transformaciones de la sociedad cubana contemporánea. De esta forma lo "local se sintoniza con las luchas identitarias y los movimientos sociales que se legitiman en su condición local y simultáneamente en su ubicación global" (ZURBANO, 2015, p. 36). ${ }^{12}$ En este contexto los temas más apremiantes de la realidad social son expuestos por los intelectuales e investigadores locales, como en el caso de Guantánamo, a través de sus vínculos con los referentes nacionales e internacionales. La influencia de sus voces de intelectuales e investigadores guantanameros en los lectores de la localidad los acerca a los vórtices de las polémicas y las complejidades de las publicaciones de la revista El Mar y la Montaña, tal y como se ilustra en esta investigación.

Dentro de este universo particular la revista El Mar y la Montaña tiene la pretensión de que en sus páginas "los lectores hallen motivación

\footnotetext{
"Este sector es uno de los sectores que más aporta al Producto Interno Bruto (PIB) del país.

${ }^{12}$ Se hace necesario acotar que la Comisión Aponte de la UNEAC en Guantánamo; la Cátedra Nelson Mandela de la Región Oriente; la Cátedra de Estudios Afrocaribeños (CEA) de la Universidad de Guantánamo, Cofradía de la Negritud, por la Unión Legal de Juristas, la Red Barrial de Afrocubanas, por el comité de ciudadanos por la Integración Racial, entre otras instituciones y proyectos realizan acciones que refuerzan la lucha antirracista.
} 
para reflexionar, convertir o disentir con lo que sus autores expresan; para pensar en definitiva cómo hacer mejor, desde el reforzamiento y defensa de lo más verdadero de nuestra cultura la sociedad en que vivimos". (FRAGUELA, 2017b, p. 2). Desde estas pretensiones el número 2 del 2017 revela el tratamiento de los asuntos raciales presentados en los artículos: El tema racial y la subversión anticubana: una actualización, por Esteban Morales Domínguez; Afrofeminismo: pensamiento y discurso afrofeminista cubano, por Daisy Rubiera Castillo; Apuntes para una cartografía en torno al debate del término afrocubano/a, por Alberto Abreu Arcia; 478 años de presencia africana en Guantánamo, por Ismael Alonso Coma; Cuestiones raciales en la cultura rastafari. Entrevista a King Mayún, por Ana Iris Aranda; ¿Avanzamos o retrocedemos en la lucha contra el racismo hoy en Cuba?, por Tomás Fernández Robaina.

El abordaje de estos tópicos no es casual. La revista se edita en Guantánamo, provincia donde existe un índice significativo de personas negras. Según los datos del censo de 2012 (ONEI, 2012) 13, la provincia es la tercera del país con la mayor población negra, con un 12,8\%, después de Santiago de Cuba, con un 14,2\% y La Habana, con 15,2\%. Es importante significar que en el 2012 la población era de 515.428 personas y para el 2019 14 de 505.854, lo que indica una disminución que puede estar sustentada, según se recoge en el censo de 2012, en los procesos de movilidad y mortalidad que hasta la fecha han ocurrido y que a nuestro juicio no altera, de manera significativa, el índice de personas negras que habitan en la localidad, aun cuando exista un relativo éxodo motivado por la pretensión de mejorar la calidad de vida. ${ }^{15}$

\footnotetext{
13 En Cuba se han realizado de 1959 hasta la fecha tres Censos en 1981, 2000 y 2012. En la actualidad aún se procesan los datos de un cuarto censo realizado en 2018 que debe ser publicado por la Oficina Nacional de Estadística e Información (ONEI) de la República de Cuba. Se debe especificar también que la información sobre color de la piel que se utiliza está registrada sobre el criterio de autodeclaración. Según se expone en el informe del Censo (2012), "la recogida de información es por declaración, atendiendo únicamente a las características y significaciones que comúnmente entiende la población. Se trata del color de la piel declarado por la persona entrevistada" (ONEI, 2012, p. 57).

14 Datos extraídos del documento: Indicadores seleccionados sobre variables demográficas cierre de 2019 (CENTRO DE INFORMAÇÕES, 2019).

${ }^{15}$ Cf. Documento Indicadores seleccionados sobre variables demográficas cierre de 2019 del CENTRO DE INFORMAÇÕES, Gobierno Provincial del Poder Popular Guantánamo.
} 
En principio, estos datos estadísticos sugieren una distorsión de la información por considerar que el criterio autodeclaración incide en su falseamiento, como consecuencia del alto nivel de subjetividad involucrado. En este punto, el color de la piel es un indicador para tener en cuenta cuando se mira hacia los sistemas de opresión que impactan sobre los sujetos. Desconsiderar estos sistemas de opresión sería negar la historia que viven las personas negras, que aún sufren los efectos del racismo. Lo que nos lleva a afirmar que "Ios problemas relativos al blanqueamiento continúan presentes dentro de nuestra realidad social. De lo contrario, cómo explicar que tantas personas que no son blancas, se resistan a asumirse como tales." (MORALES DOMÍNGUEZ, 2015, p. 322). No obstante, con las argumentaciones expuestas aquí no se pasa desapercibido el derecho que tienen la personas negras de autoidentificarse ${ }^{16}$ como un acto de resistencia ante el silenciamiento, la invisibilidad y la opresión vivida. En este caso se hace notar cómo el racismo, también, afecta la subjetividad de las personas.

En suma, los datos censales son útiles para pensar en la cantidad de personas negras que son representadas a través de los números, lo que continúa siendo un referente para el estudio y un importante punto de partida para el análisis. Así pues,

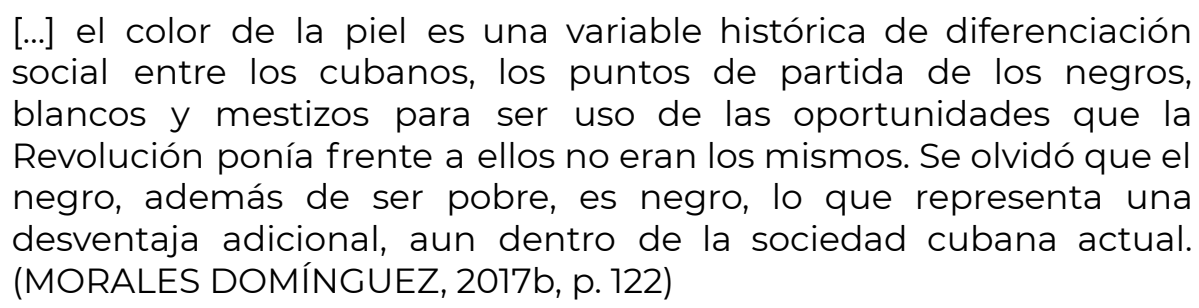

Justamente es el color de la piel, el marcador social, que enuncia el tema que será tratado del número 2/2017 de la revista. Desde la portada, a través del rostro que se presenta (FIGURA 1), se consigue pensar en los efectos que la problemática racial tiene en las personas negras.

\footnotetext{
${ }^{16}$ Cf. Serie de seminarios y conferencias. Censos 2010 y la inclusión del enfoque étnico: hacia una construcción participativa con pueblos indígenas y afrodescendientes de América Latina de la CEPAL. (POPOLO, 2009)
} 
Figura 1- Potada de la revista

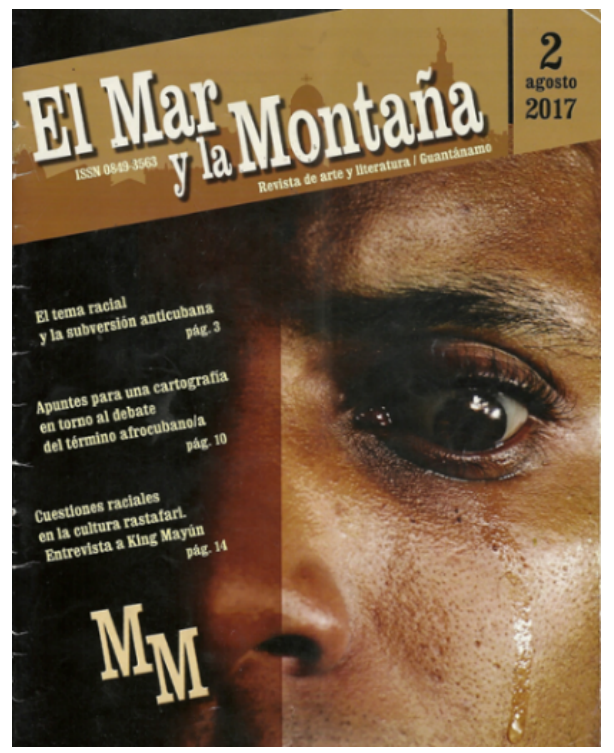

Fuente: (EL MAR Y LA MONTAÑA, 2017)

Su mirada nos conduce a uno de los trechos del texto Piel Negra, Máscaras Blancas de Franz Fanon (1973, p 90):

\begin{abstract}
¡Cochino negro!" o simplemente, "! Mira, jun negro!" Yo llegaba al mundo ansioso de encontrar un sentido a las cosas, mi alma henchida del deseo de estar en el origen del mundo, y hete aquí que yo me descubría objeto en medio de otros objetos.

Encerrado en esta objetividad aplastante, imploré otro. Su mirada liberadora, resbalando sobre mi cuerpo repentinamente sin asperezas, me devolvió una ligereza que yo creía perdida y, ausentándome del mundo, me restituyó al mundo [...]
\end{abstract}

Son esos sentimientos que se agolpan en nuestros pensamientos cuando se escudriña a través de este rostro que nos interpele con una mirada penetrante, perdida, confusa y enajenada que descubre su negritud ante un acto prejuicioso, discriminatorio y racista en un país donde el Gobierno revolucionario promulgó los mismos derechos y deberes para todas las personas sin distinción de raza o género. Así somos objetos descubiertos en medio de otros objetos, como refiere Fanon (1973). En la imagen, la persona es colocada frente al otro que la construye negro/a, se liberta, se yergue, se descubre: ¡Negra!; Soy ¡Negra! Soy y qué. Pero sobre todo se presenta innegable para pensar su situación racial en la 
realidad social donde coexiste. La imagen interroga vivencias y se cuestiona al mismo tiempo que lapida en la memoria, que no importa el tiempo y/o el espacio en que cohabitamos, las personas de piel negra se deparan con la discriminación y los prejuicios como formas elementales asociadas al racismo.

En este sentido, el análisis de las narrativas de las publicaciones del número 2/2017 de la revista se inicia desde la precepción de la imagen del negro que se repite, desde la portada hasta en la presentación visual de algunos artículos, para reforzar el ritmo de las narrativas para llamar la atención hacia el protagonismo de las personas negras, por ejemplo, como en el primer y quinto artículo (FIGURAS 2 y 6). Transitando de un tópico general a uno más específico e individual dentro de las cuestiones raciales, en los otros artículos el peso visual está en las palabras y los símbolos (FIGURAS 3, 4, 5 y 7 ).

Figura 2 - Página de presentación. Artículo 1

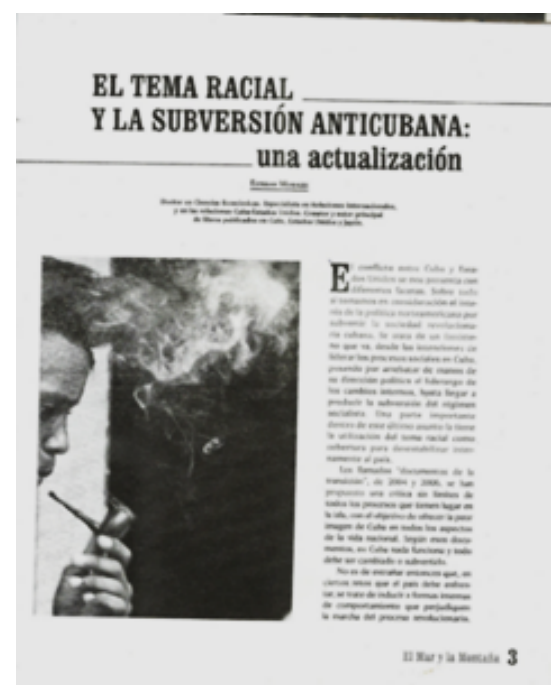

Fuente: (EL MAR Y LA MONTAÑA, 2017, p. 3)
Figura 3 - Página de presentación. Artículo 2

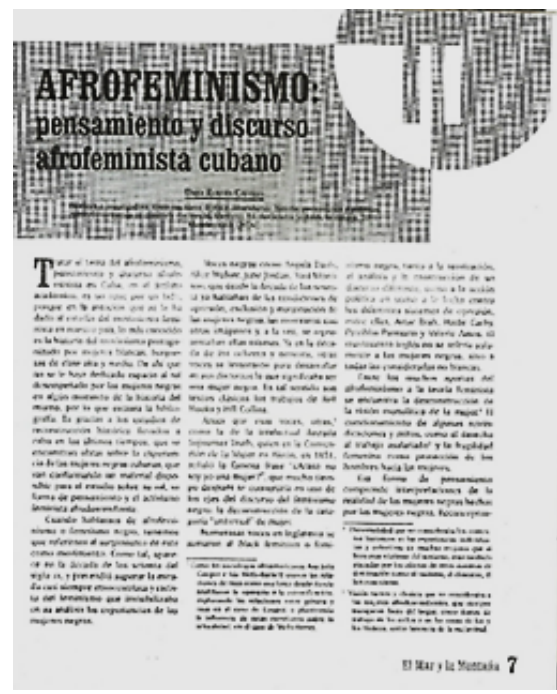

Fuente: (EL MAR Y LA MONTAÑA, 2017, p. 7) 
Figura 4 - Página de presentación. Artículo 3

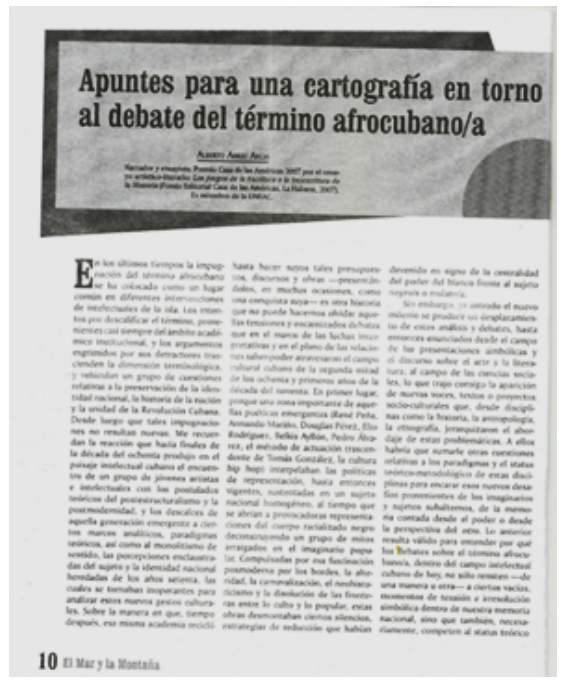

Fuente: (EL MAR Y LA MONTAÑA, 2017, p. 10)

Figura 6 - Página de presentación. Artículo 5

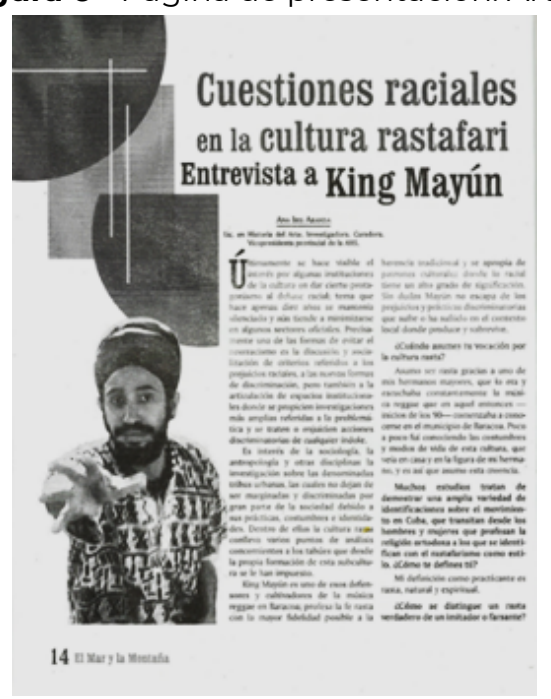

Fuente: (EL MAR Y LA MONTAÑA, 2017, p. 14)
Figura 5 - Página de presentación. Artículo 4

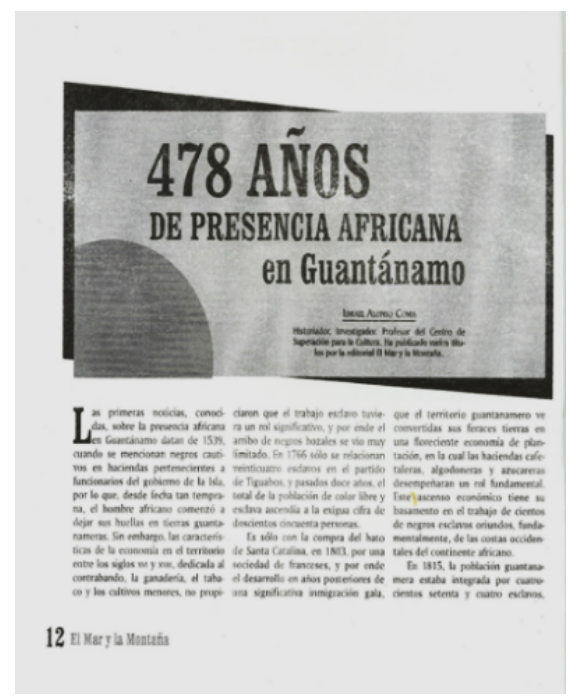

Fuente: (EL MAR Y LA MONTAÑA, 2017, p. 12)

Figura 7 - Página de presentación. Artículo 6

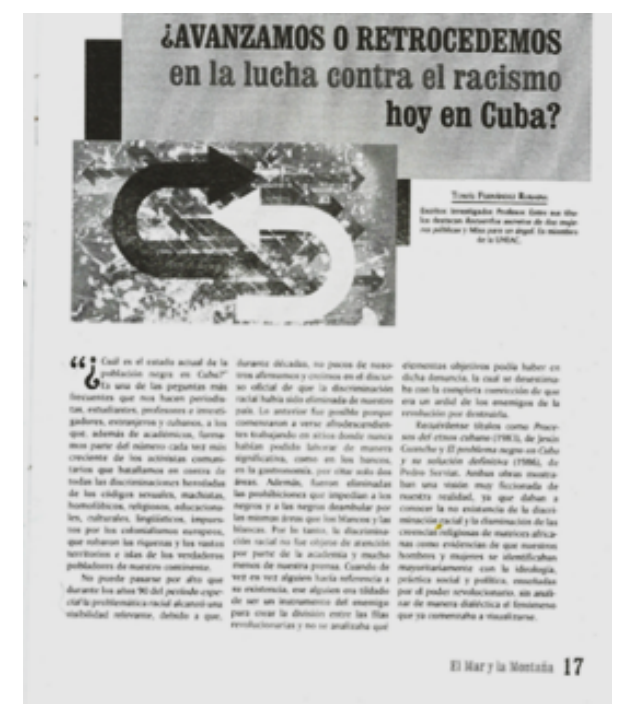

Fuente: (EL MAR Y LA MONTAÑA, 2017, p. 17)

Luego de ser presentado, el número 2/2017 de la revista y los artículos desde la percepción visual de la imagen que proponen pasamos a analizar los contenidos que subyacen en las publicaciones. Se parte de reconocer que los objetivos general y específicos son de naturaleza descriptiva y responden al análisis del contenido que se divide para su mejor comprensión por fases. Primera fase: Organización del material objeto de 
análisis; Segunda fase: Selección de las categorías, los indicadores o subcategorías y de las unidades de análisis; Tercera fase: Análisis de los materiales; y Cuarta fase: Presentación de los resultados.

Por otro lado, el objetivo general será: identificar los aspectos que particularizan el tema racial en Cuba entre los contenidos que subyacen en las publicaciones sobre racismos y discriminación racial en el número 2/2017 de la Revista de arte y literatura El Mar y la Montaña de Guantánamo; y los específicos: delimitar los subtemas tratados por los/as autores/as en los artículos presentados en el número 2/2017 de la revista; identificar los principales aspectos y argumentos presentados por los/as autores/as sobre el racismo y la discriminación racial; determinar los vínculos del tema del racismo con otros que son abordados en la temática racial.

Ahora bien, con la pretensión de concretar los objetivos específicos y por consiguiente objetivo general se enuncia la correspondencia de estos con las fases. La primera fase está destinada a delimitar los subtemas tratados por los/as autores/as en los artículos presentados en el número 2/2017 de la revista; la segunda y tercera fase para identificar los principales aspectos y argumentos presentados por los/as autores/as sobre el racismo y la discriminación racial y para determinar los vínculos del tema del racismo con otros que son abordados en la temática racial; la cuarta fase será, entonces, el espacio para la concreción del objetivo general del análisis.

\subsection{Primera fase: Organización del material objeto de análisis}

Para una mejor organización de las publicaciones se le otorgo códigos que permite hacer referencia a ellos sin necesidad de colocar el nombre del autor o de la autora y/o el título del artículo, de esta manera (TABLA 1): 
Tabla 1- Códigos de organización

\begin{tabular}{|l|l|l|l|}
\hline No. & Autor/a & Título & Código \\
\hline $\mathbf{1}$ & $\begin{array}{l}\text { Esteban Morales } \\
\text { Domínguez }\end{array}$ & $\begin{array}{l}\text { El tema racial y la subversión anticubana: una } \\
\text { actualización }\end{array}$ & A1 \\
\hline $\mathbf{2}$ & Daisy Rubiera C. & $\begin{array}{l}\text { Afrofeminismo: pensamiento y discurso } \\
\text { afrofeminista cubano }\end{array}$ & A2 \\
\hline 3 & Alberto Abreu M. & $\begin{array}{l}\text { Apuntes para una cartografía en torno al debate } \\
\text { del término afrocubano/a }\end{array}$ & A3 \\
\hline $\mathbf{4}$ & Ismael Alonso C. & 478 años de presencia africana en Guantánamo & A4 \\
\hline 5 & Ana Iris Aranda & $\begin{array}{l}\text { Cuestiones raciales en la cultura rastafari. } \\
\text { Entrevista a King Mayún }\end{array}$ & A5 \\
\hline 6 & Tomás Fernández R. & $\begin{array}{l}\text { iAvanzamos o retrocedemos en la lucha contra el } \\
\text { racismo hoy en Cuba? }\end{array}$ & A6 \\
\hline
\end{tabular}

Fuente: elaboración propia

Debe apuntarse que en el número 2/2017 de la revista además de los siete artículos publicados sobre racismo y discriminación racial se dedicó un espacio a otras materias, entre las que se destacan: $A 30$ años de nacimiento de la UNEAC en Guantánamo; La editorial El Mar y la Montaña. Los tiempos del génesis; Sello y prestancia. George Pérez y los 30 años de la revista El Mar y la Montaña; Desde la diáspora. Un encuentro con sus raíces; Una emisora cubana a pocos metros de la base naval yanqui; El eco cercano de una jornada. Concurso Regino Boti en su XXXIX edición; Acercamiento a Médula; Premios de la crítica literaria UNEAC 2017; Suerte de Luz y Un brujo de corazón quevediano, los que no son analizados aquí, pero merecen igualmente de reconocimiento.

El conocimiento de la totalidad de artículos publicados en el número 2/2017 de la revista permite hacer de manera visible la selección de la muestra. De un total de 16 artículos, que representa el 100 \% de las publicaciones se seleccionaron los 6 que abordan el tema racial, para un 37, 5 \%. De manera que solo se estará utilizando el 37, 5 \% de toda la publicación de la revista. Igualmente, se percibe con la lectura de los artículos que pueden agruparse en 4 ejes fundamentales: política e historia social ( $A 1$ y $A 6$ ); género y afrofeminismo ( $A 2$ y $A 3$ ); identidad racial (A5) e historia africana (A4). 
Los autores escogidos para publicar sus investigaciones son negros/as y mestizos/as, de ellos 2 son mujeres lo que representa el 33,3 \%. Lo que muestra que aún debe pensarse de manera más intencionada la presencia de las mujeres negras, en grados de igual proporción, en los espacios que ocupan, tanto entre los hombres negros y blancos. Igualmente, de los artículos publicados 4 ya habían sido objeto de publicación en otros medios como: A1; $A 2 ; A 3 ; A 6$.

\subsection{Segunda fase: Selección de las categorías, los indicadores o subcategorías y de las unidades de análisis}

Para conseguir identificar los principales puntos y argumentos presentados por los/as autores/as sobre el racismo y la discriminación racial y determinar los vínculos del tema del racismo con otros que son abordados en la temática racial se establecieron las siguientes categorías, subcategorías y unidades de análisis (TABLA 2).

Tabla 2- Categorías, subcategorías y unidades de análisis

\begin{tabular}{|l|l|l|}
\hline Categorías & Subcategorías & Unidades de análisis \\
\hline Estructura narrativa & $\begin{array}{l}\text { Principales temas } \\
\text { Disposición de los subtemas }\end{array}$ & $\begin{array}{l}\text { Tratamiento del tema del } \\
\text { racismo y la discriminación } \\
\text { racial }\end{array}$ \\
\hline Producción de contenido & $\begin{array}{l}\text { Principales aspectos tratados } \\
\text { Argumentos presentados }\end{array}$ & Vinculación con otros temas \\
\hline
\end{tabular}

Fuente: elaboración propia

\subsection{Tercera fase: Análisis de los materiales}

En esta fase se presentan e interpretan los datos extraídos de con la aplicación de la metodología de análisis (TABLA 3 y 4). 
Tabla 3- Análisis de la Estructura narrativa

\begin{tabular}{|c|c|c|c|}
\hline \multirow{2}{*}{$\begin{array}{l}\text { Artículos } \\
\text { (códigos } \\
\text { de org.) }\end{array}$} & \multicolumn{2}{|c|}{ Categoría: Estructura narrativa } & \multirow{2}{*}{$\begin{array}{l}\text { Unidades de análisis } \\
\text { Tratamiento del tema del } \\
\text { racismo y la discriminación } \\
\text { racial }\end{array}$} \\
\hline & Principales temas & $\begin{array}{lll}\text { Disposición de los } & \text { de } \\
\text { principales subtemas } & \end{array}$ & \\
\hline $\mathrm{A} 1$ & $\begin{array}{l}\text { La subversión } \\
\text { anticubana. El } \\
\text { conflicto entre Cuba } \\
\text { y EE. UU. }\end{array}$ & $\begin{array}{l}\text { 1. La subversión anticubana } \\
\text { 2.El tema racial como parte } \\
\text { de la estrategia política } \\
\text { subversiva de EE. UU. } \\
\text { contra Cuba }\end{array}$ & $\begin{array}{l}\text { Reconocimiento de que la } \\
\text { lucha contra el racismo y la } \\
\text { discriminación racial que se } \\
\text { esgrime desde la subversión } \\
\text { anticubana no tiene nada que } \\
\text { ver con la verdadera lucha anti } \\
\text { racial en el contexto de la } \\
\text { nación cubana. } \\
\text { La batalla de las personas } \\
\text { negras y mestizas en Cuba } \\
\text { para continuar compartiendo } \\
\text { el poder con las personas } \\
\text { blancas en igualdad de } \\
\text { condiciones. }\end{array}$ \\
\hline A2 & $\begin{array}{l}\text { Afrofeminismo y al } \\
\text { pensamiento } \\
\text { discurso feminista }\end{array}$ & $\begin{array}{l}\text { 1. Estudios sobre la historia } \\
\text { de las mujeres negras en } \\
\text { Cuba } \\
\text { 2. Pensamiento y discurso } \\
\text { feminista }\end{array}$ & $\begin{array}{l}\text { A partir del debate sobre } \\
\text { racismo para poner de } \\
\text { manifiesto la necesidad de } \\
\text { adoptar nuevas formas de } \\
\text { convivencia frente al mismo y } \\
\text { a la discriminación racial. }\end{array}$ \\
\hline A3 & $\begin{array}{l}\text { Debate sobre el } \\
\text { término } \\
\text { afrocubano/a }\end{array}$ & 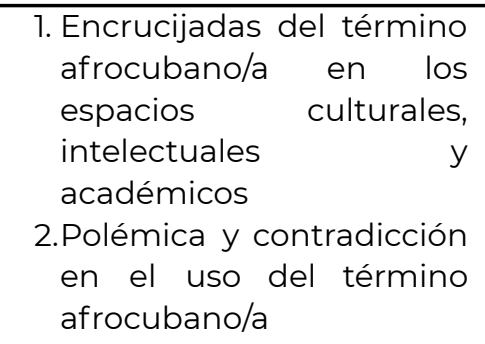 & $\begin{array}{l}\text { Reconocimiento de } \\
\text { instituciones, proyectos } \\
\text { socioculturales e intelectuales } \\
\text { que realizan acciones para } \\
\text { combatir el racismo y la } \\
\text { discriminación racial. }\end{array}$ \\
\hline A4 & $\begin{array}{l}\text { Presencia africana } \\
\text { en Guantánamo }\end{array}$ & $\begin{array}{l}\text { 1. Los africanos } \\
\text { Guantánamo } \\
\text { 2. Estudio } \\
\text { sobre lemográfico } \\
\text { africana }\end{array}$ & $\begin{array}{l}\text { La necesidad de investigar las } \\
\text { raíces africanas para entender } \\
\text { la formación de la cultura y } \\
\text { reconocer los aportes para la } \\
\text { identidad nacional. }\end{array}$ \\
\hline A5 & $\begin{array}{l}\text { Cuestiones raciales } \\
\text { en la cultura } \\
\text { rastafari en Baracoa. } \\
\text { Entrevista a King } \\
\text { Mayún }\end{array}$ & $\begin{array}{l}\text { 1. Racismo y discriminación } \\
\text { racial } \\
\text { 2.Prejuicios sobre la cultura } \\
\text { rastafari }\end{array}$ & $\begin{array}{l}\text { Exposición de experiencias } \\
\text { negativas y acciones } \\
\text { institucionales a través de las } \\
\text { cuales se vivencia el racismo } \\
\text { recreativo e institucional, la } \\
\text { discriminación y los prejuicios } \\
\text { raciales. Además de la } \\
\text { discriminación y la censuran } \\
\text { de la música reggae y otros } \\
\text { géneros alternativos. }\end{array}$ \\
\hline A6 & $\begin{array}{ll}\text { Avances } & \text { y } \\
\text { retrocesos en la } \\
\text { lucha contra el } \\
\text { racismo }\end{array}$ & $\begin{array}{l}\text { 1. Acercamiento a la } \\
\text { cuestión racial } \\
\text { 2. La lucha contra el } \\
\text { racismo en la sociedad } \\
\text { cubana }\end{array}$ & $\begin{array}{l}\text { Observancia del número } \\
\text { creciente de activistas } \\
\text { comunitarios que batallan en } \\
\text { contra de todas las } \\
\text { discriminaciones heredadas de } \\
\text { los códigos hoxuales, } \\
\text { machistas, } \\
\text { religiosos, etc. }\end{array}$ \\
\hline
\end{tabular}

Fuente: elaboración propia 
Tabla 4- Análisis de la Producción del contenido

\begin{tabular}{|c|c|c|c|}
\hline \multirow{2}{*}{$\begin{array}{l}\text { Artículos } \\
\text { (códigos } \\
\text { de org.) }\end{array}$} & \multicolumn{2}{|c|}{ Categoría: Producción de contenido } & \multirow{2}{*}{$\begin{array}{ll}\text { Unidades } & \text { de } \\
\text { análisis } & \\
\text { Vinculación } & \text { con } \\
\text { otros temas } & \end{array}$} \\
\hline & $\begin{array}{l}\text { Principales } \\
\text { aspectos } \\
\text { tratados }\end{array}$ & Argumentos presentados & \\
\hline \multirow[t]{3}{*}{ A1 } & $\begin{array}{l}\text { Comprensión } \\
\text { del fenómeno }\end{array}$ & $\begin{array}{l}\text { Hace referencia a los documentos de la } \\
\text { transición que se han propuesto ofrecer la peor } \\
\text { imagen de Cuba a través de la política } \\
\text { norteamericana, usados como instrumento por } \\
\text { ciertos grupos, supuestamente académicos que } \\
\text { siguen a la administración de EE. UU. en la } \\
\text { actual política contra Cuba. }\end{array}$ & \multirow[t]{3}{*}{$\begin{array}{l}\text { La política } \\
\text { exterior política } \\
\text { Historia pe de } \\
\text { Relaciones EE. UU. } \\
\text { Cuba con E } \\
\text { Gobernabilidad }\end{array}$} \\
\hline & $\begin{array}{l}\text { Estrategia } \\
\text { política } \\
\text { subversiva de } \\
\text { EE. UU. contra } \\
\text { Cuba }\end{array}$ & $\begin{array}{l}\text { Discute como la política de la administración } \\
\text { norteamericana contra Cuba trata de situar a los } \\
\text { negros y mestizos de Cuba como víctimas del } \\
\text { Estado, Gobierno y Partido Comunista de Cuba. } \\
\text { Explica cómo la política social desplegada por la }\end{array}$ & \\
\hline & $\begin{array}{ll}\text { Atención } & \text { al } \\
\text { tema racial }\end{array}$ & $\begin{array}{l}\text { Revolución reconoció a todos, los derechos a la } \\
\text { educación salud, seguridad social y acceso al } \\
\text { empleo, lo cual beneficio a ciudadanos pobres, } \\
\text { negros y mestizos por igual como la gran } \\
\text { mayoría de ellos. }\end{array}$ & \\
\hline \multirow[t]{3}{*}{$\mathrm{A} 2$} & $\begin{array}{l}\text { Estudios sobre } \\
\text { la historia de } \\
\text { las mujeres } \\
\text { negras en } \\
\text { Cuba }\end{array}$ & $\begin{array}{l}\text { Expresa que los estudios sobre la historia de las } \\
\text { mujeres negras son escasos, al mismo tiempo } \\
\text { que argumenta que la historia del movimiento } \\
\text { feminista en Cuba que más se conoce está } \\
\text { protagonizada por las mujeres blancas. }\end{array}$ & \multirow[t]{3}{*}{$\begin{array}{l}\text { Afrofeminismo } \\
\text { Género y } \\
\text { diversidad racial } \\
\text { Desigualdad } \\
\text { social }\end{array}$} \\
\hline & $\begin{array}{l}\text { Movimiento, } \\
\text { pensamiento y } \\
\text { discurso } \\
\text { feminista }\end{array}$ & $\begin{array}{l}\text { Relaciona nombres de las precursoras del } \\
\text { pensamiento femenino negro cubano. Abre un } \\
\text { espacio para exponer el por qué cuando } \\
\text { hablamos de feminismo o feminismo negro, } \\
\text { tenemos que referirnos al surgimiento de este } \\
\text { como movimiento en otras latitudes, al mismo } \\
\text { tiempo que relaciona los aportes del } \\
\text { pensamiento feminista para comprender las } \\
\text { interpretaciones de la realidad de las mujeres } \\
\text { negras hechas por mujeres negras. }\end{array}$ & \\
\hline & $\begin{array}{l}\text { Beneficios de } \\
\text { los diferentes } \\
\text { proyectos y } \\
\text { acciones del } \\
\text { Gobierno } \\
\text { revolucionario } \\
\text { para todas las } \\
\text { mujeres }\end{array}$ & $\begin{array}{l}\text { Muestra como luego del triunfo de la Revolución } \\
\text { independientemente de todos los beneficios de } \\
\text { los diferentes proyectos y acciones que puso el } \\
\text { gobierno revolucionario, apremiaba una nueva } \\
\text { forma de conciencia intelectual que rompiera el } \\
\text { silencio que sobre las mujeres negras que se } \\
\text { había mantenido históricamente en la } \\
\text { historiografía cubana. }\end{array}$ & \\
\hline A3 & $\begin{array}{l}\text { Análisis del } \\
\text { término } \\
\text { afrocubano/a }\end{array}$ & $\begin{array}{l}\text { Análisis de las discusiones sobre el término en el } \\
\text { campo cultural cubano presupone que la } \\
\text { historia, la evolución e itinerarios que describe } \\
\text { este término en su tránsito por el campo } \\
\text { intelectual cubano del siglo XX y XXI, examina } \\
\text { aquellos momentos en que el término ha } \\
\text { servido como mecanismo explicativo de los } \\
\text { procesos históricos-culturales. }\end{array}$ & $\begin{array}{l}\text { Afrofeminismo } \\
\text { Género y } \\
\text { diversidad racial } \\
\text { Desigualdad } \\
\text { social } \\
\text { Diáspora } \\
\text { afrocubana }\end{array}$ \\
\hline
\end{tabular}




\begin{tabular}{|c|c|c|c|}
\hline & $\begin{array}{l}\text { Encrucijadas } \\
\text { del término } \\
\text { afrocubano/a } \\
\text { en los espacios } \\
\text { culturales, } \\
\text { intelectuales y } \\
\text { académicos. }\end{array}$ & $\begin{array}{l}\text { Término afrocubano colocado como un lugar } \\
\text { común en diferentes intervenciones de } \\
\text { intelectuales en la Isla. Al mismo tiempo que } \\
\text { declara que los intentos por descalificar el } \\
\text { término provienen casi siempre del ámbito } \\
\text { académico institucional. } \\
\text { Detractores que trascienden la dimensión } \\
\text { terminológica, y vehiculan un grupo de } \\
\text { cuestiones relativas a la preservación de la } \\
\text { identidad nacional, la historia de la nación y la } \\
\text { unidad de la Revolución Cubana. }\end{array}$ & \\
\hline & $\begin{array}{l}\text { Polémica y } \\
\text { contradicción } \\
\text { en el uso del } \\
\text { término } \\
\text { afrocubano/a }\end{array}$ & $\begin{array}{l}\text { El término afrocubano/a se presenta como } \\
\text { peyorativo que erosiona la identidad nacional, } \\
\text { dicho rótulo se coloca como el lugar teórico que } \\
\text { describe y donde se dilucidan un grupo de } \\
\text { fricciones entre las viejas y las nuevas } \\
\text { epistemologías raciales. }\end{array}$ & \\
\hline \multirow[t]{4}{*}{ A4 } & $\begin{array}{l}\text { Llegada de los } \\
\text { africanos. }\end{array}$ & $\begin{array}{l}\text { Presencia africana en Guantánamo datan de } \\
1539 \text { cuando se mencionan negros cautivos en } \\
\text { haciendas pertenecientes a funcionarios del } \\
\text { Gobierno de la isla. }\end{array}$ & \multirow[t]{4}{*}{$\begin{array}{l}\text { Identidad } \\
\text { Nacional } \\
\text { Diáspora africana }\end{array}$} \\
\hline & $\begin{array}{l}\text { Estudio } \\
\text { demográfico } \\
\text { sobre la } \\
\text { población } \\
\text { africana. }\end{array}$ & $\begin{array}{l}\text { Estudio demográfico que transita desde } 1539 \\
\text { hasta } 1879 \text { para referenciar el número en } \\
\text { creciente de africanos y sus descendientes en } \\
\text { Guantánamo y los compara con la cantidad de } \\
\text { blanco. }\end{array}$ & \\
\hline & $\begin{array}{l}\text { Ocupaciones } \\
\text { laborales. }\end{array}$ & $\begin{array}{l}\text { Estudio padrón de los habitantes del pueblo en } \\
\text { los que se revelan las ocupaciones laborales de } \\
\text { muchas de estas personas: tabaqueros, sastres, } \\
\text { alfarero, herrero, labrador, músico, lavandera, } \\
\text { etcétera. Trabajos poco calificados en su mayoría } \\
\text { y de bajo nivel adquisitivo. }\end{array}$ & \\
\hline & $\begin{array}{l}\text { Procedencia } \\
\text { de los } \\
\text { africanos } \\
\text { esclavizados }\end{array}$ & $\begin{array}{l}\text { Los africanos provenían de las costas de Angola, } \\
\text { Nigeria y Congo. }\end{array}$ & \\
\hline \multirow[t]{2}{*}{ A5 } & $\begin{array}{l}\text { Racismo y } \\
\text { discriminación } \\
\text { racial }\end{array}$ & $\begin{array}{l}\text { Experiencias negativas con respecto a la } \\
\text { discriminación racial, sobre todo con algunos } \\
\text { funcionarios del gobierno y de las instituciones } \\
\text { culturales que aún discriminan y censuran la } \\
\text { música reggae y otros géneros alternativos. }\end{array}$ & \multirow[t]{2}{*}{$\begin{array}{l}\text { Identidad racial } \\
\text { Ciudadanía } \\
\text { Desigualdad } \\
\text { social }\end{array}$} \\
\hline & $\begin{array}{l}\text { Prejuicios } \\
\text { sobre } \\
\text { cultura } \\
\text { rastafari }\end{array}$ & $\begin{array}{l}\text { Prejuicios sobre esta cultura están en el } \\
\text { imaginario de las personas que solo miran el } \\
\text { exterior de los seres humanos y hacen falsas } \\
\text { propaganda y juicios apresurados sobre Rasta. } \\
\text { La cultura rasta se ha transformado en una } \\
\text { moda, las vestimentas, los dreadlocks son } \\
\text { usados para hacer un elemento de atracción } \\
\text { frente a la avalancha de turistas que cada año } \\
\text { llegan al Caribe. El hecho de ser negro ya es mal } \\
\text { mirado qué decir de los que visten e imitan para } \\
\text { atraer turistas. }\end{array}$ & \\
\hline
\end{tabular}




\begin{tabular}{|c|c|c|c|}
\hline \multirow[t]{2}{*}{$A 6$} & $\begin{array}{l}\text { Acercamiento } \\
\text { a la cuestión } \\
\text { racial }\end{array}$ & $\begin{array}{l}\text { Aspectos que ilustran los momentos que } \\
\text { marcan la problemática racial en la sociedad } \\
\text { cubana, y del reconocimiento de que falta } \\
\text { mucho para combatir el racismo y sus históricas } \\
\text { proyecciones, discriminatorias y prejuiciosas, en } \\
\text { contra de la población de origen africano desde } \\
\text { la colonia hasta hoy. }\end{array}$ & \multirow[t]{2}{*}{$\begin{array}{l}\text { Política interna } \\
\text { Políticas públicas }\end{array}$} \\
\hline & \begin{tabular}{l}
\multicolumn{3}{l}{ Ejemplos } \\
sobre la lucha \\
contra el \\
racismo en la \\
sociedad \\
cubana
\end{tabular} & $\begin{array}{l}\text { Acciones generadas por la Cofradía de la } \\
\text { Negritud, por la Unión Legal de Juristas, la Red } \\
\text { Barrial de Afrocubanas, por el comité de } \\
\text { ciudadanos por la Integración Racial entre otras } \\
\text { expresiones fehacientes de que hay un } \\
\text { movimiento antirracista, antidiscriminación } \\
\text { encabezada por líderes y lideresas, activistas } \\
\text { comunitarios o académicos. }\end{array}$ & \\
\hline
\end{tabular}
Fuente: elaboración propia

\subsection{Cuarta fase: Presentación de los resultados}

Estos estudios raciales vienen a enriquecer la historiografía cubana escrita sobre la temática, a través de investigaciones que descubren variados aspectos que han constituido brechas ocultas y/o poco exploradas, presentadas por mucho tiempo desde una perspectiva institucional parcializada y desde el poder. Estos, también, revelan la existencia de una gran pluralidad teórica, y de una diferenciación de enfoques que se apoyan en las herramientas teóricas y metodológicas provenientes de la Historia Social, la Sociología y los Estudios Culturales, fundamentalmente.

El tratamiento del tema del racismo y la discriminación racial pasa por el prisma del reconocimiento de que la lucha que se esgrime contra el racismo y la discriminación racial desde la subversión anticubana no tiene nada que ver con la verdadera lucha anti racial en el contexto de la nación cubana; la batalla de las personas negras y mestizas en Cuba es de continuar compartiendo el poder en igualdad de condiciones; la necesidad de adoptar nuevas formas de convivencia frente al racismo y a la discriminación racial que se vivencia; además de la urgencia de que incremente el activismos comunitario, las instituciones, proyectos socioculturales e intelectuales que realizan acciones para combatir el racismo y la discriminación racial, junto con exposición de experiencias 
negativas y acciones institucionales a través de las cuales se vivencia el racismo recreativo e institucional, la discriminación y los prejuicios raciales.

Los subtemas presentados están dispuestos según el orden de aparición de los argumentos presentados. De manera que se observa una amplia variedad de aspectos raciales que son transversalizados por el legado africano (africanidad); la transculturación (mestizaje y cubanidad); las relaciones de poder en los niveles económicos, sociales y oficiales; la desigualdad social; la reproducción de estereotipos y prejuicios raciales; la situación de desigualdad y diferenciación social que vive la población negra. Simultáneamente se vincula a temas como: Política exterior; Historia política; Relaciones de Cuba con EE. UU.; Afrofeminismo; Género y diversidad racial; Desigualdad social; Género y diversidad racial; Diáspora afrocubana; Identidad Nacional; Diáspora africana; Identidad racial; Ciudadanía; Política interna y Políticas públicas.

En algunas de las narrativas discursivas, sobre todo en aquellas escritas por hombres, se revela la existencia de un marcado uso del término negro para hacer alusión a las personas negras, lo que desconsidera la presencia de las mujeres negras en dichos discursos y limita la posibilidad de percibir un enfoque de género. De igual modo se reconoce la existencia de un discurso racial que se materializa en lo oficial, social y académico, como niveles discursivos que dotan de corporeidad a la problemática racial en la sociedad cubana. ${ }^{17}$ Lo que confirma que en este proceso la negritud y la conciencia de lo negro se construyó entre dos vertientes, por un lado, la representación de la negritud que resurge del discurso oficial de la homogeneidad que deviene del proyecto político y por otro, entre lo social y lo académico donde la conciencia de lo negro lleva a la comprensión de la afirmación de la negritud de cara a su otredad "lo blanco" en una lógica de dominación (ABREU, 2012). Dicho en otras palabras, en las publicaciones

\footnotetext{
${ }^{17}$ En este sentido el análisis de la negritud y la conciencia de lo negro se construye entre dos vertientes, por un lado, la representación de la negritud que resurge del discurso oficial de la homogeneidad que deviene del proyecto político y por otro, entre lo social y lo académico donde la conciencia de lo negro lleva a la comprensión de la afirmación de la negritud de cara a su otredad "Io blanco" en una lógica de dominación (ABREU, 2012).
} 
se vislumbran las dimensiones multifacéticas de la raza en la cultura y vida diaria cubanas, que hacen resaltar la importancia de esta discusión.

\section{Ideas (in)conclusas}

A partir de la consulta de los referentes bibliográficos que constituyen antecedentes para el estudio que se realizó, y tomando en consideración los resultados del análisis de los contenidos de las publicaciones sobre el tema racial de la revista El Mar y la Montaña aquí presentadas, se levantaron algunas cuestiones, que son concebidas como un rutero para próximas indagaciones:

- Desde las Editoriales Provinciales se contribuye con publicaciones donde los lectores encuentran voces polémicas y diversas que dialogan sobre las cuestiones que matizan el tema racial en Cuba.

- La problemática racial en la sociedad cubana contemporánea forma parte de los debates públicos y se refleja también en los discursos (académicos, sociales y oficiales). Sin embargo, las voces que indagan en las brechas del tema racial y deconstruyen concepciones sobre la raza, demandan la urgencia de mayor apertura en los espacios de discusiones a nivel nacional y local.

- Muchos estudiosos/as, creadores/as, actores sociales, etc. desempeñan papeles decisivos como protagonistas de la realidad social, desde lo académico, lo político, lo cultural y el activismo, reivindican posturas oficiales sobre las identidades nacionales y raciales cubanas.

- Las interpretaciones históricas, el análisis sociocultural y político presente en estas publicaciones acentúan las aspiraciones de justicia social y logros singulares del proyecto social cubano. De modo que sugieren la apertura de un mayor espacio de discusión con una 
agenda antirracista que exprese nuevas demandas emancipatorias y ciudadanas.

\section{Referencias}

ABREU ARCIA; Alberto, Apuntes para una cartografía en torno al debate del término afrocubano/a, En: Revista El Mar y la Montaña, Guantánamo, Cuba, n. 2, p. 10-12, ago. 2017.

ABREU MORALES, Reynier. La cuestión del negro como dimensión identitaria: Cuba 1990-2011, 2012. p.124. Tesis de Maestría en Ciencias Sociales. México, D. F., 2012.

ALMEIDA JUNCO, Yulexis «Género y racialidad: Una reflexión obligada en la Cuba de hoy». In: RUBIERA CASTILLO, Daysi y MARTIATU TERRY, Inés María (comp.). Afrocubanas: historia, pensamiento y prácticas culturales. La Habana: Editorial de Ciencias Sociales, p.133-149, 2011.

ALMEIDA, Silvio. O que é racismo estrutural? Belo Horizonte (MG): Letramento. 2019.

ALONSO COMA; Ismael. 478 años de presencia africana en Guantánamo. Revista El Mar y la Montaña, n. 2, p. 12-14, ago. 2017.

ARANDA; Ana Iris. Cuestiones raciales en la cultura rastafari. Entrevista a King Mayún. Revista El Mar y la Montaña, n. 2, p. 14-17, ago. 2017.

BARDIN, Laurence. A análise de conteúdo. 3.ed. Lisboa: Edições 70, 2004.

BOBES, Cecilia. Cuba y la cuestión racial. Perfiles Latinoamericanos, n. 8, pp. 115-139. ene/jun, 1996

DAVIS, Angela. Mulheres, raça e classe. São Paulo: Boitempo, 2016. 
DE LA FUENTE, Alejandro. A Nation for All: Race, inequality, and politics in Twentieth Century Cuba. Chapel Hill (N.C): The University of North Carolina Press, 2001.

CASTRO Ruz, Fidel. Estamos en condiciones de librar una guerra de todo el pueblo para la cultura. Periódico Granma, La Habana. Primera Edición.1999.

Disponible en: https://dialnet.unirioja.es/descarga/articulo/7246136.pdf . Accedido en 12 agosto 2020.

CENTRO DE INFORMACIÓN. Indicadores seleccionados sobre variables demográficas a cierre de 2019. Guantánamo: Gobierno Provincial del Poder Popular Guantánamo, 2019.

CUBA. Acuerdo VIII-75, de 15 nov, 2017. Asamblea Nacional del Poder Popular. Conceptualización del modelo económico y social cubano de desarrollo socialista, La Habana. Disponible en https://www.gacetaoficial.gob.cu/es/acuerdo-viii-75-de-2017-de-asamblea-n acional-del-poder-popular. Accedido en 18 marzo 2021.

EARLY, James. Prólogo. Identidad racial, democracia participativa y Revolución en la Cuba del siglo XXI. Desafíos de la problemática racial en Cuba. In: GUILLARÓN CARRILLO, Paula. Raza y Racismo en Cuba. Recuentos para un debate desde Temas. Cuba. Ed. Temas. p.8. 2015.

ESPINA PRIETO, Rodrigo; RODRÍGUEZ RUIZ, Pablo. Raza y desigualdad en la Cuba actual. Revista Temas, v. 45, n. 3, p. 45, ene/feb. 2006. Disponible en: http://www.afrocubaweb.com/Razas-racismo-Cuba-Colectivo.pdf

Accedido en 10 sept. 2020.

FANON, Frantz, Piel Negra, Máscaras Blancas, Editorial Abraxas. Buenos Aires, $1973 . \quad$ Disponible en: https://repositorio.ufsc.br/bitstream/handle/123456789/1579/6739688-FrantzFanon-Piel-Negra-Mascaras-Blancas.pdf?sequence=1 . Accedido en 11 agosto 2020. 
FERNÁNDEZ ROBAINA, Tomás. ¿Avanzamos o retrocedemos en la lucha contra el racismo hoy en Cuba? Revista El Mar y la Montaña, n. 2, p. 17-20, ago. 2017

FERNÁNDEZ ROBAINA, Tomás. La batalla contra el racismo en la Cuba de hoy. América sin nombre, n. 19, p. 121-125, 2014. Disponible en: http://www.cervantesvirtual.com/research/num-19-diciembre-de-2014/7464 470e-3ced-4377-83c3-3a37453f79ec.pdf . Accedido en 12 abril 2020.

FRAGUELA, José Raúl. Nota del Editor. Revista El Mar y la Montaña, n. 2, p. 2 ago. 2017 .

FRAGUELA, José Raúl. Sello y presencia. George Pérez y los 30 años de la revista El Mar y la Montaña. Revista El Mar y la Montaña, n. 2, p. 29-31, ago. 2017b.

MATURELL RUIZ, Mariurka: "La Historiografía de las Migraciones. Un análisis a los textos publicados por la Editorial El Mar y la Montaña en Guantánamo", Revista Caribeña de Ciencias Sociales, oct. 2016. Disponible en http://www.eumed.net/rev/caribe/2016/10/migraciones.html. Accedido 21 agosto 2020.

MESA-LAGO, Carmelo. Problemas sociales y económicos en Cuba durante la crisis y la recuperación. Revista de la CEPAL. n. 86, p. 183-205, ago. 2005.

MOORE, Carlos. Racismo e sociedade: novas bases epistemológicas para entender o racismo. Belo Horizonte: Mazza Edições, 2007

MORALES DOMÍNGUEZ, Esteban. Desafíos de la problemática racial en Cuba. Raza y Racismo en Cuba. Recuentos para un debate desde Temas, La Habana. Fundación Fernando Ortiz. p.312, 2015.

MORALES DOMÍNGUEZ, Esteban. Desafíos de la problemática racial en Cuba. Raza y racismo: antología de caminos. La Habana: Editorial Caminos, p. 119-129, 2017a. 
MORALES DOMÍNGUEZ, Esteban. El tema racial y la subversión anticubana: una actualización. Revista El Mar y la Montaña, n. 2, p. 3-6, ago. 2017b.

MOREIRA, Adilson. Racismo recreativo. São Paulo: Pólem, 2019.

MOREJÓN, Nancy. Mujer negra, Negro. América Sin Nombre. Boletín de la Unidad de Investigación de la Universidad de Alicante: «Recuperaciones del mundo precolombino y colonial en el siglo XX hispanoamericano» n. 19, diciembre 2014. Disponible en: http://www.cervantesvirtual.com/research/num-19-diciembre-de-2014/7464 470e-3ced-4377-83c3-3a37453f19ec.pdf . Accedido en 12 abril 2020.

NARANJO OROVIO, Consuelo; GONZÁLEZ-RIPOLL NAVARRO, María Dolores; RUIZ DEL ÁRBOL MORO, María (Ed.). Racismo ayer y hoy. In: EI Caribe origen del mundo moderno. España: UNESCO/Connected Worlds. s/d.

Disponible

en:

https://docecalles.com/wp-content/uploads/2020/03/El_Caribe_Origen_del_ mundo_moderno.pdf Accedido en 11 jun. 2020.

ONEI (OFICINA NACIONAL DE ESTADÍSTICA E INFORMACIÓN). Informe Nacional. Censo de Población y Viviendas. 2012. Disponible en: http://www.onei.gob.cu/sites/default/files/informe_nacional_censo_0.pdf.

Accedido en 21 agosto 2020.

PARRA FONTANILLES, Rissell. La editorial Revista El Mar y la Montaña. Los tiempos del Génesis. Revista El Mar y la Montaña, n. 2, p. 27-28, ago. 2017.

PARTIDO COMUNISTA DE CUBA. Lineamientos de la Política Económica y Social del Partido y la Revolución, La Habana, 2011

PÉREZ, Esther; LUEIRO, Marcel. Raza y racismo: antología de caminos. La Habana: Editorial Caminos, p.388, 2017.

POPOLO, Fabiana del. Censos 2010 y la inclusión del enfoque étnico: hacia una construcción participativa con pueblos indígenas y afrodescendientes de América Latina. (Serie Seminarios y conferencias). 
CEPAL - No. 57 C. Santiago de Chile, 2009. Disponible en https://core.ac.uk/download/pdf/38673133.pdf. Accedido en 12 agosto 2020.

RENSOLI Medina, Rolando. Racialidad y racismo en Cuba: discriminación y prejuicios; prevención y enfrentamiento. Comisión José A. Aponte. Boletín no. 36, Unión de Artistas y Escritores de Cuba (UNEAC), marzo 2015.

RIBEIRO, Djamila. Quem tem medo do feminismo negro? São Paulo: Companhia das Letras, 2018.

RUBIERA Castillo, Daisy. Afro feminismo: pensamiento y discurso afro feminista cubano, En: Revista El Mar y la Montaña, Nro. 2, p. 7-10, ago. 2017. RUIZ RUIZ, Jorge. Sociological Discourse Analysis: Methods and Logic. Forum Qualitative Sozialforschung / Forum: Qualitative Social Research, v. 10, n. 2, mayo 2009. ISSN 1438-5627. Disponible en: <https://www.qualitative-research.net/index.php/fqs/article/view/1298/2776>. Accedido en 29 Agosto 2020. doi: http://dx.doi.org/10.17169/fas-10.2.1298 .

ZURBANO, Roberto. Racismo vs. socialismo en Cuba: un conflicto fuera de lugar (apuntes sobre/contra el colonialismo interno). MERIDIONAL Revista Chilena de Estudios Latinoamericanos n.4 abr. 2015. 